\title{
Editorial
}

\section{The Added Value of Multidisciplinary Care for Patients with Pancreatic Cancer}

\author{
Douglas B. Evans, MD, ${ }^{1}$ Christopher H. Crane, $\mathrm{MD},{ }^{2}$ Chusilp Charnsangavej, $\mathrm{MD},{ }^{3}$ and \\ Robert A. Wolff, MD ${ }^{4}$
}

\author{
${ }^{1}$ Department of Surgical Oncology, Unit 444, The University of Texas M. D. Anderson Cancer Center, 1515 Holcombe Blvd, \\ Houston, TX 77030, USA \\ ${ }^{2}$ Department of Radiation Oncology, The University of Texas M. D. Anderson Cancer Center, Houston, TX, USA \\ ${ }^{3}$ Department of Diagnostic Imaging, The University of Texas M. D. Anderson Cancer Center, Houston, TX, USA \\ ${ }^{4}$ Department of Gastrointestinal Medical Oncology, The University of Texas M. D. Anderson Cancer Center, Houston, TX, USA
}

The article by Pawlik and colleagues in this issue of Annals of Surgical Oncology provides objective data in support of a multimodality approach to the care of the pancreatic cancer patient. The current manuscript builds on the long-standing tradition of excellence in the care of this disease established by John Cameron and takes advantage of their unique institutional talents in diagnostic imaging (Elliot Fishman) and pathology (Ralph Hruban). Indeed, an obvious potential criticism of this manuscript is that they can do things at Johns Hopkins which simply can not be done elsewhere and therefore, this work is not translatable to other centers with less experience. However, we would argue that the specific results presented by Pawlik and colleagues are translatable to other less experienced centers if definitions and templates were to be developed and uniformly applied to the care of patients with pancreatic cancer throughout this country. For example:

1. The clinical/radiographic stage of disease was changed in $19 \%$ of patients after review of prereferral imaging and when necessary, repeat imaging interpreted by an experienced radiologist. To assign a clinical/radiographic stage to a patient (and their CT images) assumes that the multidisciplinary group has agreed on the definitions of resectable, locally advanced (to include borderline

Published online June 11, 2008.

Address correspondence and reprint requests to: Douglas B. Evans, MD; E-mail: devans@mdanderson.org

Published by Springer Science+Business Media, LLC $\odot 2008$ The Society of Surgical Oncology, Inc. resectable) and metastatic disease. As the manuscript infers, this is rarely the case. In fact, there was recently a consensus conference coordinated by Dr. Jean-Nicolas Vauthey and supported by the SSO and the AHPBA to generate working definitions of these stages of disease; this important manuscript is forthcoming. If physicians of different specialties can agree on the radiographic stages of disease, then stage specific treatment is possible, and over time, more uniform. The clinical/radiographic staging system in use at our institution is presented in Table 1. However, accurate staging is possible only if the crosssectional imaging studies are done well and interpreted accurately. Accurate interpretation of CT or MRI images by radiologists of significantly less experience than Dr. Fishman requires a report template to insure that all necessary information is contained in the report - information needed to accurately apply the proper stage of disease. The template in use at our institution appears in Table 2. Such working definitions allow for patients to be initially evaluated by physicians of any specialty and their disease extent accurately determined.

2. The treatment recommendation was altered in $24 \%$ of patients based on repeat imaging and multidisciplinary review. If we agree that for most solid tumors, treatment is stage specific, then the clinician needs to know 3 basic pieces of information to develop a treatment recommendation: histologic diagnosis, stage of disease, and performance status of the patient. The multidisciplinary 
TABLE 1. The clinical/radiographic staging system used at MDACC for adenocarcinoma of the pancreatic head and uncinate process

\begin{tabular}{|c|c|c|c|c|c|}
\hline \multirow[b]{2}{*}{ Clinical stage of disease } & \multirow{2}{*}{$\begin{array}{l}\text { AJCC } \\
\text { stage }\end{array}$} & \multicolumn{4}{|c|}{ Tumor-vessel relationship on computed tomography } \\
\hline & & SMA & Celiac axis & $\mathrm{CHA}^{* *}$ & SMV-PV \\
\hline $\begin{array}{l}\text { Resectable (all } 4 \text { required } \\
\text { to be resectable)* }\end{array}$ & $\mathrm{I} / \mathrm{II}$ & $\begin{array}{l}\text { Normal tissue } \\
\text { plane between } \\
\text { tumor and vessel }\end{array}$ & $\begin{array}{l}\text { Normal tissue } \\
\text { plane between } \\
\text { tumor and vessel }\end{array}$ & $\begin{array}{l}\text { Normal tissue } \\
\text { plane between } \\
\text { tumor and vessel }\end{array}$ & $\begin{array}{l}\text { Patent (may include tumor } \\
\text { abutment or encasement) }\end{array}$ \\
\hline $\begin{array}{l}\text { Borderline resectable } \\
\text { (only } 1 \text { of the } 4 \text { required) }\end{array}$ & III & Abutment & Abutment & $\begin{array}{l}\text { Abutment or short } \\
\text { segment encasement }\end{array}$ & $\begin{array}{l}\text { May have short } \\
\text { segment occlusion if } \\
\text { reconstruction possible }\end{array}$ \\
\hline $\begin{array}{l}\text { Locally advanced (only } \\
1 \text { of the } 4 \text { required) }\end{array}$ & III & Encasement & Encasement & $\begin{array}{l}\text { Extensive encasement } \\
\text { with no technical } \\
\text { option for reconstruction }\end{array}$ & $\begin{array}{l}\text { Occluded with no } \\
\text { technical option for } \\
\text { reconstruction }\end{array}$ \\
\hline
\end{tabular}

Abbreviations: CHA, common hepatic artery; SMV-PV, superior mesenteric vein-portal vein confluence.

Definitions: abutment, $\leq 180^{\circ}$ or $\leq 50 \%$ of the vessel circumference; encasement, $>180^{\circ}$ or $>50 \%$ of the vessel circumference.

* Assumes the technical ability to resect and reconstruct the SMV, PV, or SMV-PV confluence when necessary. Others may consider tumorvein abutment/encasement which results in deformity of the vein as borderline resectable.

** Assumes normal vascular anatomy; for example, encasement of the CHA is not a limitation in performing PD when there is an uninvolved replaced right HA arising from the SMA.

Reprinted with permission from: Wolff RA, et al. Adjuvant Therapy for Adenocarcinoma of the Pancreas: Analysis of Reported Trials and Recommendations for Future Progress. In press: Ann surg Oncol.

TABLE 2. An example of the CT template in use at MDACC for the interpretation of CT scans in patients with a presumed pancreatic malignancy

\begin{tabular}{ll}
\hline \multicolumn{1}{c}{ CT Characteristic } \\
\hline Tumor size & Measured in cm \\
Tumor location & Cephalad head, caudal head, uncinate, body, and tail \\
Tumor-vein (SMV, PV, SMV-PV confluence) relationship & Abutment $\left(\leq 180^{\circ}\right)$, encasement $\left(>180^{\circ}\right)$ or occlusion \\
Tumor-artery (SMA, celiac axis, CHA, & Abutment $\left(\leq 180^{\circ}\right)$, encasement $\left(>180^{\circ}\right)$ or occlusion \\
$\quad$ replaced hepatic artery) relationship & Resectable, borderline resectable, locally advanced \\
Extent of local tumor based on above descriptions & Note all aberrant vessels \\
Hepatic arterial anatomy & Presence, absence, or borderline (indeterminate for metastasis); \\
Extent of extra-pancreatic disease and location & location in liver, peritoneum, lung \\
\hline
\end{tabular}

Abbreviations: SMV, superior mesenteric vein; PV, portal vein; SMV-PV, superior mesenteric vein-portal vein confluence; SMA, superior mesenteric artery; CHA, common hepatic artery.

TABLE 3. The general treatment schema used to guide stage-specific therapy at MDACC for patients with adenocarcinoma of the pancreas

\begin{tabular}{|c|c|c|}
\hline Clinical stage of disease & AJCC stage & Treatment options \\
\hline \multirow[t]{3}{*}{ Resectable } & \multirow[t]{3}{*}{$\mathrm{I} / \mathrm{II}$} & 1. Protocol-based, stage-specific neoadjuvant therapy \\
\hline & & $\begin{array}{l}\text { 2. Off-protocol neoadjuvant therapy (usually gemcitabine-based } \\
\text { chemoradiation) }\end{array}$ \\
\hline & & $\begin{array}{l}\text { 3. Surgery followed by protocol-based adjuvant therapy for } \\
\text { patients who have undergone an } \mathrm{R} 0 / \mathrm{R} 1 \text { resection }\end{array}$ \\
\hline \multirow[t]{2}{*}{ Borderline resectable } & \multirow[t]{2}{*}{ III } & 1. Protocol-based, stage-specific multimodality therapy \\
\hline & & $\begin{array}{l}\text { 2. Off-protocol therapy usually consisting of a gemcitabine doublet } \\
\text { followed by chemoradiation and surgery (if no disease progression) }\end{array}$ \\
\hline \multirow[t]{3}{*}{ Locally advanced } & \multirow[t]{3}{*}{ III } & 1. Protocol-based stage-specific multimodality therapy \\
\hline & & 2. Off-protocol chemoradiation if pain is uncontrolled \\
\hline & & $\begin{array}{l}\text { 3. Off-protocol systemic therapy followed by chemoradiation (if no } \\
\text { disease progression following systemic therapy) }\end{array}$ \\
\hline \multirow[t]{3}{*}{ Metastatic } & \multirow[t]{3}{*}{ IV } & 1. Protocol-based systemic therapy \\
\hline & & 2. Off-protocol systemic therapy \\
\hline & & 3. Best supportive care \\
\hline
\end{tabular}


review/interaction (whether in an outpatient clinic or a tumor board environment) enhances crosstalk between specialties and allows for the development of consensus regarding stage-specific (and to some degree institution-specific) treatment algorithms (Table 3). Having physicians of different specialties reach consensus on treatment recommendations requires that they have meaningful academic interchange - the multidisciplinary clinic clearly serves that purpose, but other potentially less time-consuming alternatives (multidisciplinary outpatient centers which are disease-specific not specialty-specific, weekly multidisciplinary conferences, office space allocation which considers disease orientation not just departmental affiliation) may also be available.

3. Enrollment in clinical trials was greatly enhanced by the development of the multidisciplinary clinic. Point well taken, and for a disease with such an aggressive natural history such as pancreatic cancer, attention to the enrollment of patients in clinical trials is our obligation (not our option). However, the success of such efforts is clearly influenced by the presence or absence of an academic agenda, infrastructure support for clinical trials, and patterns of reimbursement. This may be a much more complicated problem to fix for many institutions than the other two examples cited above.

Last, it is important to emphasize the value of leadership and interpersonal relationships in the success or failure of multidisciplinary disease-site program development. For those who have the group dynamics that exist among Dr. Pawlik and his colleagues (even at much smaller levels), such efforts are fun, academically stimulating, and self-perpetuating. When group dynamics are less favorable, it may be difficult to maintain consistent focus on the important goals of patient care, clinical trials, and professional and programmatic development.

Dr. Pawlik and colleagues are to be congratulated for bringing objective evidence of benefit to a system of multidisciplinary care that should be made possible in many hospitals outside Baltimore. 